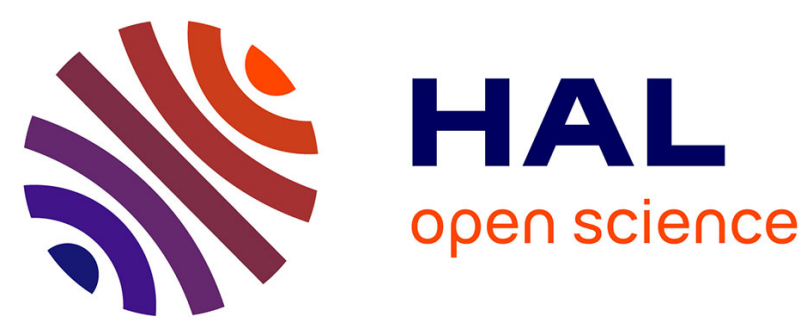

\title{
Tool wear analysis and improvement of cutting conditions using the high-pressure water-jet assistance when machining the Ti17 titanium alloy \\ Yessine Ayed, Guénaël Germain, Amine Ammar, Benoit Furet
}

\section{To cite this version:}

Yessine Ayed, Guénaël Germain, Amine Ammar, Benoit Furet. Tool wear analysis and improvement of cutting conditions using the high-pressure water-jet assistance when machining the Ti17 titanium alloy. Precision Engineering, 2015, 42, pp.294-301. 10.1016/j.precisioneng.2015.06.004 . hal-02486151

\section{HAL Id: hal-02486151 \\ https://hal.science/hal-02486151}

Submitted on 20 Feb 2020

HAL is a multi-disciplinary open access archive for the deposit and dissemination of scientific research documents, whether they are published or not. The documents may come from teaching and research institutions in France or abroad, or from public or private research centers.
L'archive ouverte pluridisciplinaire HAL, est destinée au dépôt et à la diffusion de documents scientifiques de niveau recherche, publiés ou non, émanant des établissements d'enseignement et de recherche français ou étrangers, des laboratoires publics ou privés. 


\title{
Tool wear analysis and improvement of cutting conditions using the high-pressure water-jet assistance when machining the Ti17 titanium alloy
}

\author{
Y. Ayed ${ }^{\mathrm{a}, *}$, G. Germain ${ }^{\mathrm{a}}, \mathrm{A}$. Ammar ${ }^{\mathrm{a}}$, B. Furet $^{\mathrm{b}}$ \\ a Arts et Métiers ParisTech, LAMPA, 2 bd du Ronceray, 49035 Angers Cedex, France \\ b IUT Nantes, IRCCyN, 2 av. du Professeur Jean Rouxel, 44475 Carqefou, France
}

\section{A B S T R A C T}

This paper presents experimental results concerning the machinability of the titanium alloy Ti17 with and without high-pressure water jet assistance (HPWJA) using uncoated WC/Co tools. For this purpose, the influence of the cutting speed and the water jet pressure on the evolution of tool wear and cutting forces have been investigated. The cutting speed has been varied between $50 \mathrm{~m} / \mathrm{min}$ and $100 \mathrm{~m} / \mathrm{min}$ and the water jet pressure has been varied from 50 bar to 250 bar. The optimum water jet pressure has

Keywords: been determined, leading to an increase in tool life of approximately 9 times. Compared to conventional

Tool wear lubrication, an increase of about $30 \%$ in productivity can be obtained.

High pressure

Cutting forces

Titanium alloy

\section{Introduction}

Titanium alloys have been widely studied due to their remarkable properties, notably their strength/density ratio which presents interesting advantages in the aviation and aerospace fields. However, the machining of these alloys is particularly challenging, which has a direct impact on productivity, surface integrity and tool life.

The high chemical reactivity and the low thermal conductivity of these alloys present favourable conditions for tool wear. In addition, the high temperature in the cutting zone and the high cutting forces accentuate the evolution of the wear. According to [16], there is a critical temperature at which the degradation of the cutting tool is accelerated. This is around $740^{\circ} \mathrm{C}, 760^{\circ} \mathrm{C}$ and $900^{\circ} \mathrm{C}$ for $\mathrm{WC} / \mathrm{Co}$, PCD and CBN respectively. This limits the choice of cutting tool materials and coatings. Regardless of the type of machined material, the tool must fulfil a number of characteristics to have better wear resistance:

- Maintain good mechanical properties at high temperatures (hardness, rigidity and tenacity).

\footnotetext{
* Corresponding author.

E-mail address: yessine.ayed@ensam.eu (Y. Ayed).
}

- Have a high chemical inertia to resist the high chemical affinity of some alloys.

- Have an adapted cutting geometry.

According to $[11,19-21]$ the uncoated tungsten carbide WC/Co seems to be a good choice for the machining of titanium alloys.

High-pressure water jet assistance presents an efficient solution to decelerate tool wear and to enhance tool life. Using this technique, the increase in tool life for titanium alloys varies between $185 \%$ [3] and $460 \%$ and it can reach $780 \%$ when machining Inconel 718 [8,15]. In addition, HPWJA allows, among other things, to effectively lubricate the cutting zone and thus to reduce the temperature in the tool by more than $40 \%$ [13]. Furthermore, the fragmentation of chips is ensured. The study of orthogonal cutting with high pressure coolant assistance [12] showed that chip breaking is controlled by the nozzle diameter used and the pressure of the water jet.

The effect of the lubricant type has been tested by [17]. The study is based on the comparison of the performance of the water-soluble oil and the neat oil during the high-pressure cooling assisted machining of $\mathrm{Ti}-6 \mathrm{Al}-4 \mathrm{~V}$. The respective tool life for the conventional lubrication, neat oil and water-soluble oil are $4 \mathrm{~min}, 5 \mathrm{~min}$ and $14 \mathrm{~min}\left(V_{c}=100 \mathrm{~m} / \mathrm{min}, f=0.2 \mathrm{~mm} / \mathrm{rev}, P=100 \mathrm{bar}\right.$, $d_{\text {nozzle }}=0.8 \mathrm{~mm}$ ). The influence of the direction of the lubricant jet and flow rate has been the object of the study carried out by [7] for the turning of AISI 1045 steel. When the fluid was applied on 


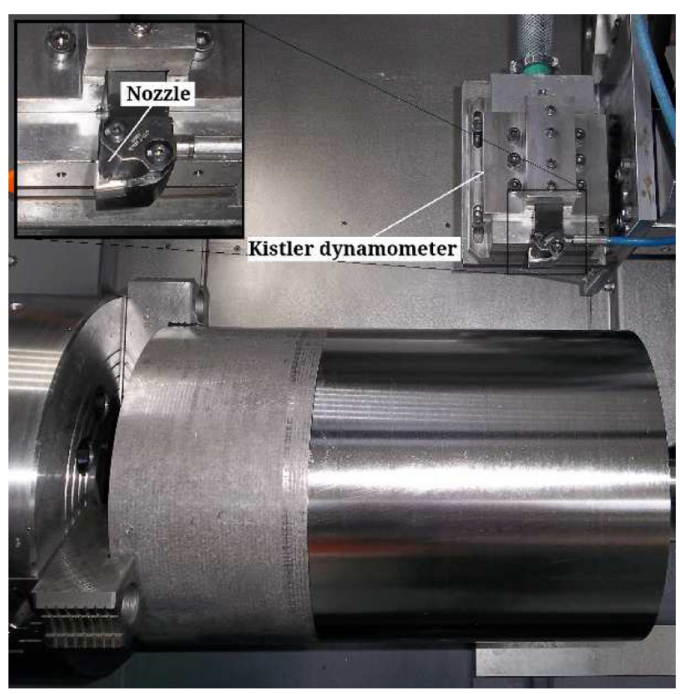

Fig. 3. Experimental setup.

Tool wear has been followed and controlled by using a stereo binocular microscope and a scanning electron microscope, by monitoring the cutting forces. Over 270 measurements related to the 20 tests have been carried out. At the beginning of the experimental work, a series of repeatability tests were performed. The same types of wear was observed and the measurement error of the flank wear is estimated to be $0.02 \mathrm{~mm}$. Fig. 4 shows the main wear types.

\section{Tool wear tests at $V_{C}=50 \mathrm{~m} / \mathrm{min}$}

For the initial cutting speed of $50 \mathrm{~m} / \mathrm{min}$, three lubrication types were selected: conventional lubrication (Conv-Lub), and two highpressure lubrication conditions ( $P=100$ bar and $P=250$ bar). Fig. 5 shows the evolution of flank wear (VB) as a function of the machining time. For the total duration of the test (30 min), flank wear does not exceed $0.26 \mathrm{~mm}$. It can also be noted that with HPWJA ( $250 \mathrm{bar}$ ), the evolution of flank wear is stable in the beginning of the test. However, towards the end of the test, its evolution becomes very rapid. Moreover, with a pressure of 100 bar, the flank wear is still less than $0.2 \mathrm{~mm}$ [1]. Hence, it would be interesting to test other lubrication pressures to investigate their effect on tool wear.

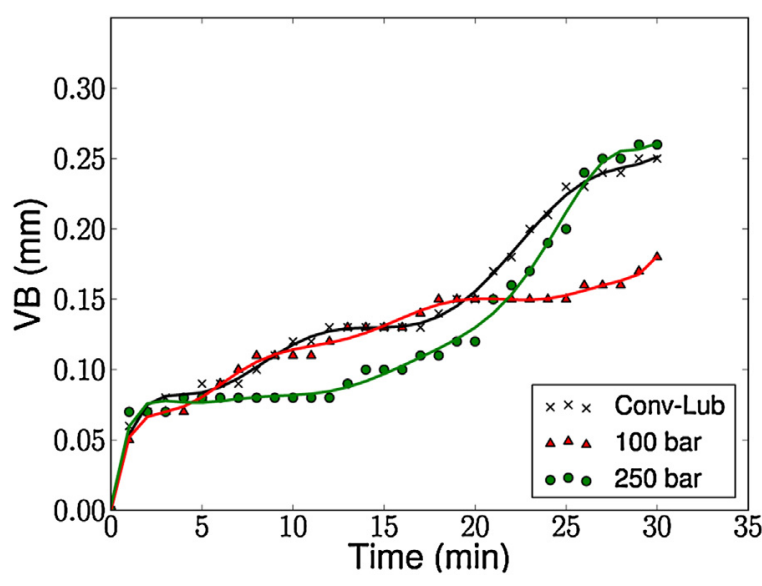

Fig. 5. Flank wear evolution, $V_{C}=50 \mathrm{~m} / \mathrm{min}$.

Fig. 6 shows the SEM images of the tool rake face at the end of the three trials. For the conventional lubrication condition, layers of deposits and a large notch have been noticed on the cutting edge (Fig. 6(a)).

Bahatt et al. [2] explains that the combination of the high contact pressure between the tool and the chip, coupled with the high cutting temperature, causes welding to occur between the surface of the chip and the rake face. Devillez et al. [6] proposes the same explanation.

Childs [4] shows that the sticking between the chip and the carbide grains is due to diffusion between the chip and the tool. Thus, an increase in the cutting temperature promotes the diffusion between the tool and the chip. It is true that the adherent layers could protect the tool. However, when the formation of these layers reaches a saturation state, they are pulled-out. When this happens, they are detached along with fragments of the tool, thus causing adhesive wear [6,22].

However, with the high-pressure lubrication, a crater is visible on the tool rake face (Fig. 6(b) and (c)). Furthermore, the buildup of the adherent layers has been reduced due to the action of the lubricant jet. In fact, The lubricant jet pulls out the adherent layers leading to the acceleration of the crater wear [1,7]. However, under these conditions the evolution of the flank wear remains low compared to conventional lubrication. Over time, this will weaken

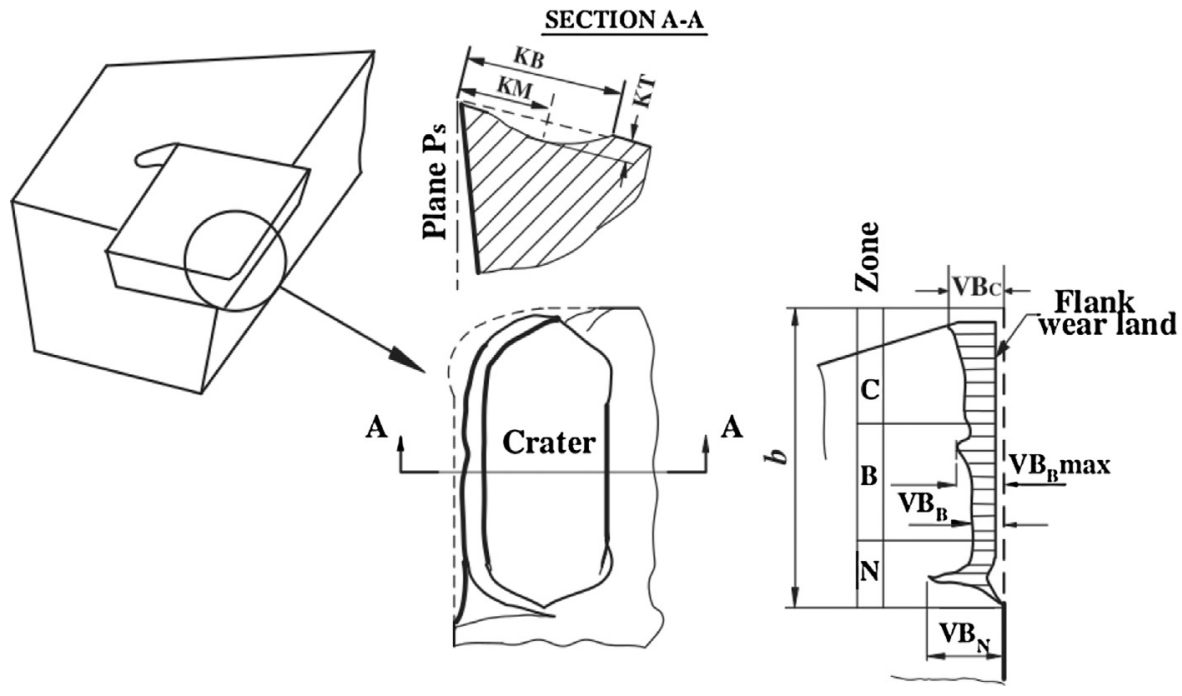

Fig. 4. Types of wear [14]. 


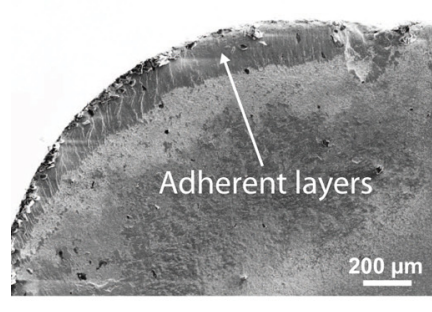

(a)

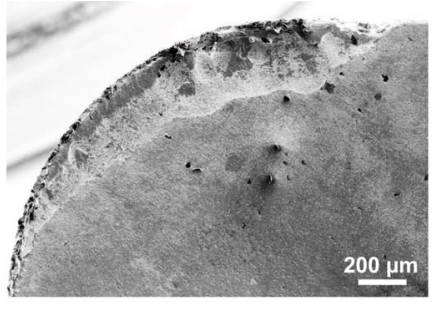

(b)

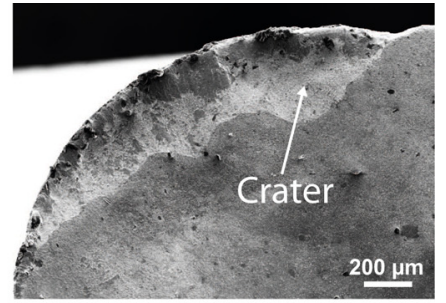

(c)

Fig. 6. Crater wear, (a) conventional lubrication, (b) 100 bar, (c) 250 bar.

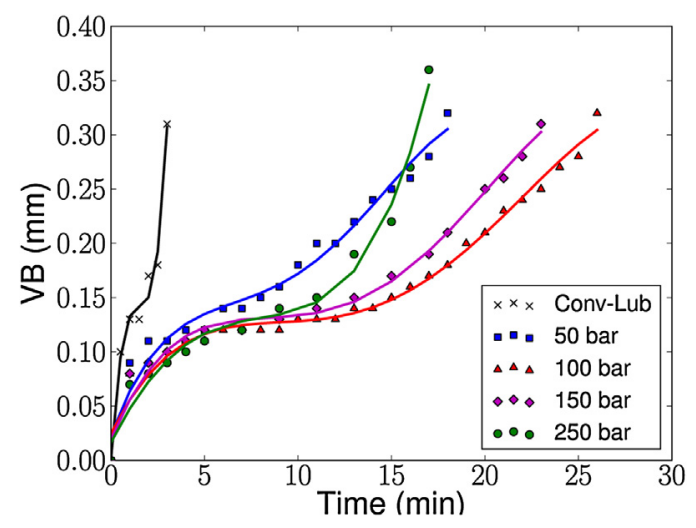

Fig. 7. Flank wear evolution, $V_{C}=75 \mathrm{~m} / \mathrm{min}$.

the tool insert. The cutting edge will eventually collapse under the action of the cutting forces.

Increasing the pressure of the water jet causes faster tearing away of the deposed layers leading to the acceleration of the crater wear. Hence, the optimal pressure should be determined which, firstly, cools the tool and allows access to the cutting area (a pressure of 50 bar seems to be insufficient in this case). Secondly, it reduces the flank wear (a pressure of 100 bar gives the best results).

Still, this does not affect the global tool life. In fact, tool wear is more severe with conventional lubrication due to the higher cutting temperature and the higher friction coefficient compared to HPWJA. Under these conditions, the wear rate is higher than in HPWJA due to the activation of many wear mechanisms. In fact with conventional lubrication the combination of high cutting forces and high temperature causes the rapid collapse of the cutting edge, especially for high cutting speeds.

\section{Tool wear tests at $V_{C}=75 \mathrm{~m} / \mathrm{min}$}

For these tests the cutting speed was increased by $50 \%$ relative to the reference cutting speed of $50 \mathrm{~m} / \mathrm{min}$. Fig. 7 shows the evolution of flank wear for the five lubrication conditions. For the conventional lubrication condition, tool wear increases very quickly and the tool life does not exceed 3 min. However, with high-pressure lubrication, tool life has been greatly improved. Indeed, the best performance has been recorded at 100 bar.

Table 4 summarizes the results of the wear tests. It can be noticed that tool life has been multiplied by 8 fort the pressure

Table 4

Tool life at $V_{C}=75 \mathrm{~m} / \mathrm{min}$.

\begin{tabular}{llllll}
\hline & Conv-Lub & 50 bar & 100 bar & 150 bar & 250 bar \\
\hline Tool life $(\min )$ & 3 & 18 & 26 & 23 & 16 \\
\hline
\end{tabular}

of 100 bar. However, increasing the pressure beyond 100 bar does not improve the results.

The formation and the evolution of notch wear have also been noted. When the notch wear exceeds $0.21 \mathrm{~mm}$, burrs are formed on the workpiece. Fig. 8 shows the evolution of notch wear (VBn). In fact, it gives the mean values and provides a global estimation over the machining time.

The variation of the cutting and the axial forces, for different lubrication conditions, are plotted in Fig. 9. It shows that $F_{a}$ and $F_{C}$ increase as a function of machining time and consequently the tool wear. Furthermore, for an increase of $0.3 \mathrm{~mm}$ of flank wear, the variation of the axial force $\Delta F_{a}$ reaches $350 \mathrm{~N}$ while the variation of the cutting force $\Delta F_{C}$ exceeds $100 \mathrm{~N}$. It was also noted that the evolution of the axial and the cutting forces follows the evolution of flank wear, the same trends are noticed. Furthermore, when the axial force exceeds $600 \mathrm{~N}$, the corresponding flank wear is about $0.3 \mathrm{~mm}$ for all tests. So, the axial force is more sensitive to flank wear than the cutting force. Fig. 10 shows the evolution of the axial force as a function of the flank wear for different lubrication conditions.

Globally, the use of high-pressure assistance significantly increases the tool life. However, when the jet pressure exceeds 100 bar, the tool life begins to decrease (compared to its value at 100 bar), and the surface of the workpiece is affected by scratches. These scratches are most likely caused by the impact of fragmented chips. Moreover, when the pressure increases, the chips are broken into smaller pieces and projected at higher speeds. This may intensify the scratches on the surface of the workpiece.

It is necessary to note that this phenomenon is observed in the context of this study on the Ti17 alloy. However, this might not be the case for other alloys and materials.

\section{Tool wear tests at $V_{C}=88 \mathrm{~m} / \mathrm{min}$}

For this series of tests, the cutting speed is increased by $75 \%$ relative to the reference cutting speed. Fig. 11 shows the evolution of

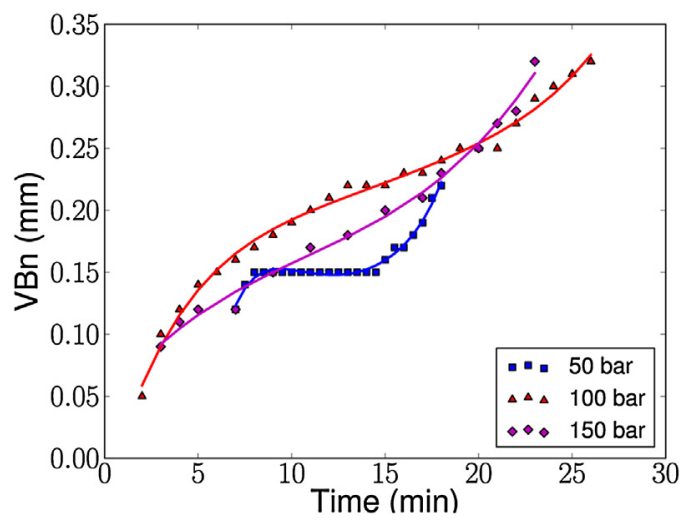

Fig. 8. Notch wear evolution, $V_{C}=75 \mathrm{~m} / \mathrm{min}$. 


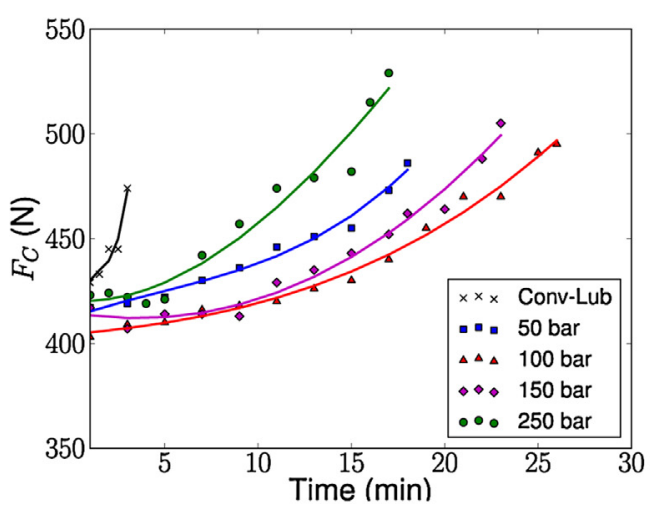

(a)

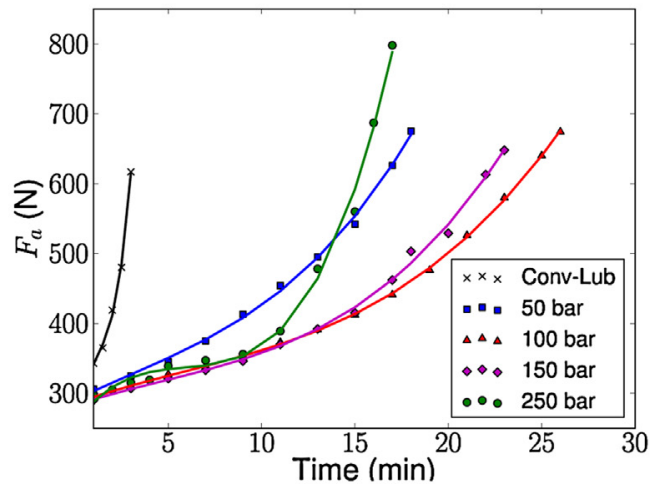

(b)

Fig. 9. Evolution of the axial and the cutting forces.

Table 5

Tool life at $V_{C}=88 \mathrm{~m} / \mathrm{min}$.

\begin{tabular}{llllll}
\hline & Conv-Lub & 50 bar & 100 bar & 150 bar & 250 bar \\
\hline Tool life $(\mathrm{min})$ & 1 & 6 & 9 & 8.5 & 9 \\
\hline
\end{tabular}

flank wear for the different conditions. With conventional lubrication, the Ti17 alloy is not machinable at this cutting speed because the tool life is about $1 \mathrm{~min}$. In fact, the flank wear evolves linearly reaching $0.45 \mathrm{~mm}$ in only $90 \mathrm{~s}$. However, with high-pressure assistance the tool life has been increased significantly with values up to $9 \mathrm{~min}$ and with a linear evolution of the flank wear. Indeed, the curves do not exhibit the catastrophic evolution of wear.

Fig. 12 shows the rake and flank faces of the tool at the end of the wear tests. With Conventional lubrication, the cutting edge has completely collapsed. Indeed, tool wear seems to be very severe. In contrast, with HPWJA, tool wear is more regular.

Table 5 shows the effect of the high-pressure water jet assistance on increasing the tool life. With a pressure of 50-bar, tool life is multiplied by 6 and with the pressure of 100 bar it is multiplied by 9 . According to the flank wear curves, increasing the pressure seems to have no effect beyond 100 bar. However, as for the cutting speed of $75 \mathrm{~m} / \mathrm{min}$, scratches have been observed on the workpiece. They are more intense and accompanied by the welding of chip fragments on the workpiece.

As it has been previously noted, under the action of the water jet, chips are fragmented into very small fragments which do not exceed $3 \mathrm{~mm}$, some of which are recycled by passing between the cutting edge and the workpiece. These could be welded on the workpiece, as shown in Fig. 13.

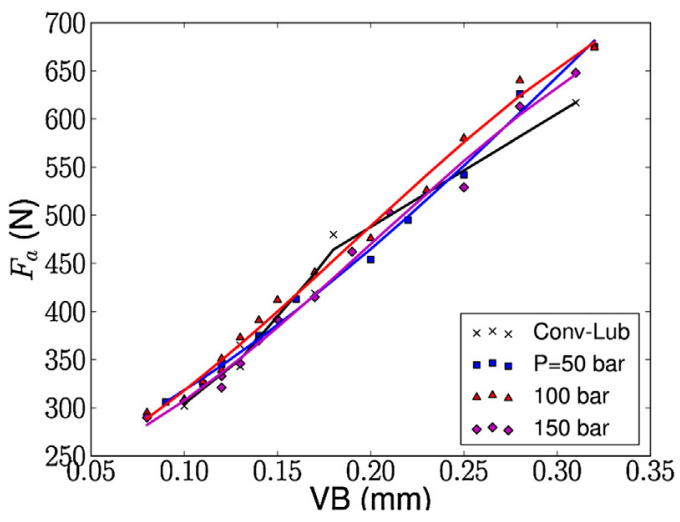

Fig. 10. Evolution of the axial force as a function of flank wear $\left(V_{C}=75 \mathrm{~m} / \mathrm{min}\right)$.
The analysis of the cutting force evolution during the machining time shows the existence of peaks. These peaks may correspond to the phenomenon of chips recycling. The change in cutting force $\Delta F$ can reach $50 \mathrm{~N}$. Fig. $14(\mathrm{a})$ and (b) respectively shows the evolution of the cutting force after $5 \mathrm{~min}$ and $9 \mathrm{~min}$ of high-pressure water jet assisted machining. Furthermore, from these curves, it can be noted that the frequency of force peaks has been increased. Hence, it can be concluded that the chip recycling frequency has also been increased. The approximate number of these peaks has been multiplied by two.

Flank wear could be accelerated with the phenomenon of chip recycling which could also explain the curves of Figs. 5 and 7.

\section{Tool wear tests at $V_{C}=100 \mathrm{~m} / \mathrm{min}$}

For this series of experiments, the cutting speed has been doubled compared to the reference cutting speed. According to Fig. 15, tool life does not exceed $4.5 \mathrm{~min}$ even with high-pressure water jet assistance. Thus, it can be deduced that the effectiveness of the assistance has been greatly reduced. In fact, the lubricant jet cannot dissipate the heat generated in the cutting zone and the wear continues to evolve.

However, compared with conventional lubrication, Table 16 shows that the tool life can be multiplied by 9 with a pressure of 100 bar. With conventional lubrication, the tool lasts only a few seconds before collapsing. As has already been noticed, for pressures exceeding $100 \mathrm{bar}$, the surface of the workpiece is affected by scratches and welded fragments of chips.

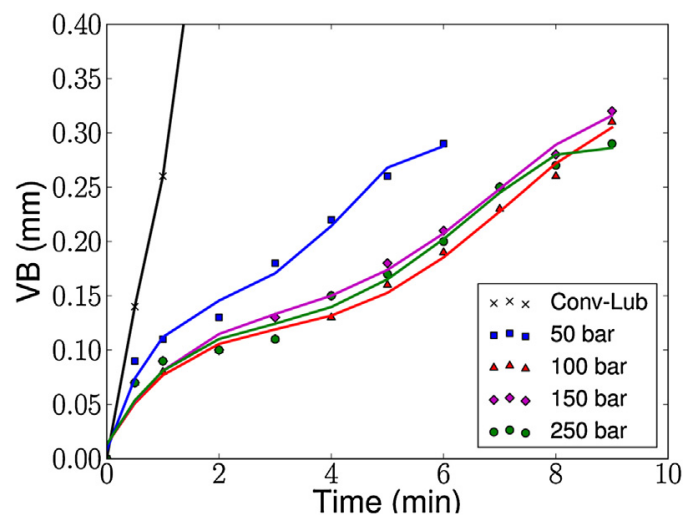

Fig. 11. Flank wear evolution, $V_{C}=88 \mathrm{~m} / \mathrm{min}$. 
Conv-Lub
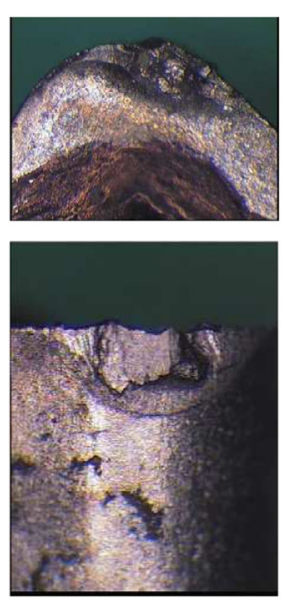

$1 \mathrm{~min}$

\section{0 bar}
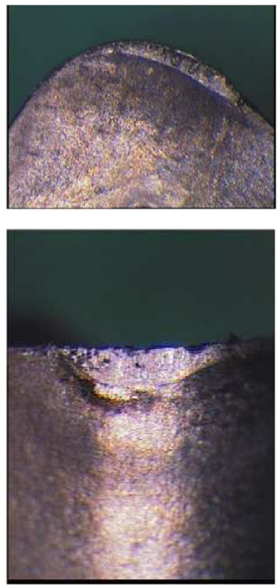

$6 \mathrm{~min}$
100 bar
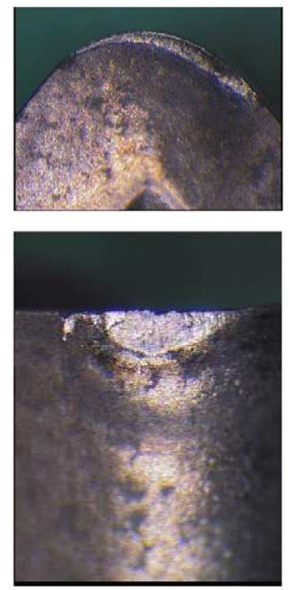

$9 \min$
150 bar
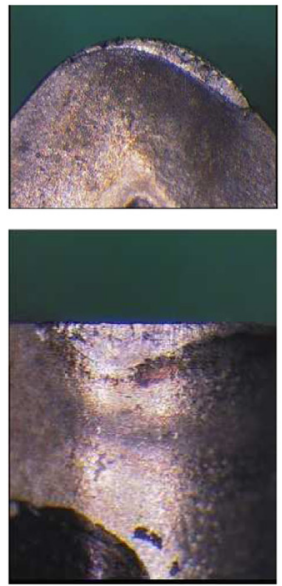

$8.5 \mathrm{~min}$
250 bar
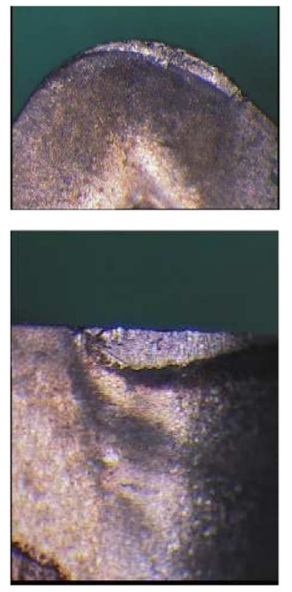

$9 \min$

Fig. 12. Flank and crater wear at the end of tool life, $V_{C}=88 \mathrm{~m} / \mathrm{min}$.
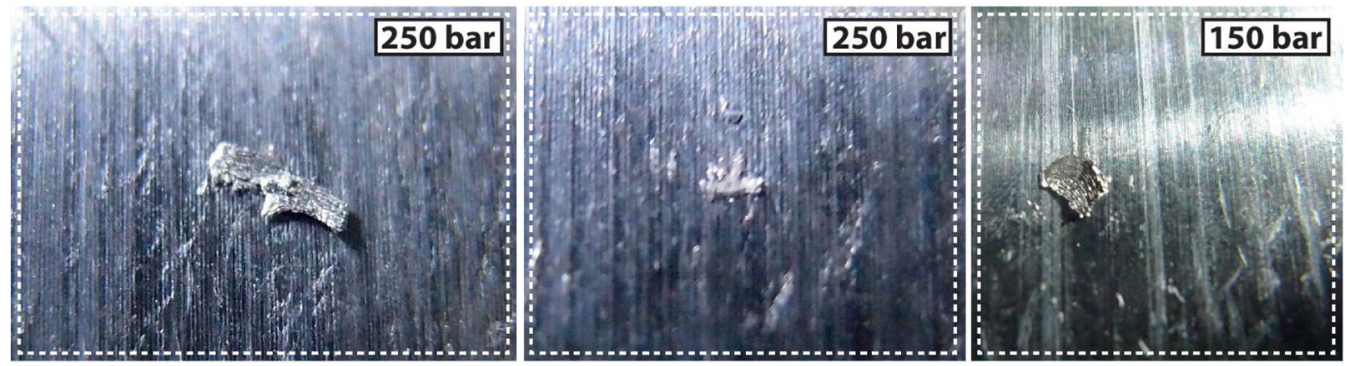

Fig. 13. Scratches and welded chip fragments on the surface of the workpiece (150 bar and 250 bar).

\section{Discussion}

Fig. 17 summarizes the results obtained for the cutting speeds of $75 \mathrm{~m} / \mathrm{min}, 88 \mathrm{~m} / \mathrm{min}$ and $100 \mathrm{~m} / \mathrm{min}$. The first finding is that tool life drops rapidly when cutting speed increases. This is because the increase of the cutting speed causes an increase of the cutting power and so the dissipation of heat in the workpiece as well as the tool. The additional generation of heat causes a temperature rise in the cutting zone. Thereafter, the wear mechanisms which are activated at high temperatures dominate, thus accelerating tool wear.
In the case of conventional lubrication, wear takes place very quickly and causes the collapse of the cutting edge after a few minutes $\left(V_{C}=75 \mathrm{~m} / \mathrm{min}\right)$, or after a few seconds $\left(V_{C}=100 \mathrm{~m} / \mathrm{min}\right)$. The high-pressure water jet allows the continuous cooling of the cutting area. However, the effectiveness of the assistance decreases as the cutting speed becomes more important. Certainly, high-pressure water jet assistance can increase the tool life greatly compared to the conventional lubrication, but it reaches its limits for high cutting speeds.

In the range of cutting speeds in which assistance has certain advantages and is still effective, an optimum pressure can be

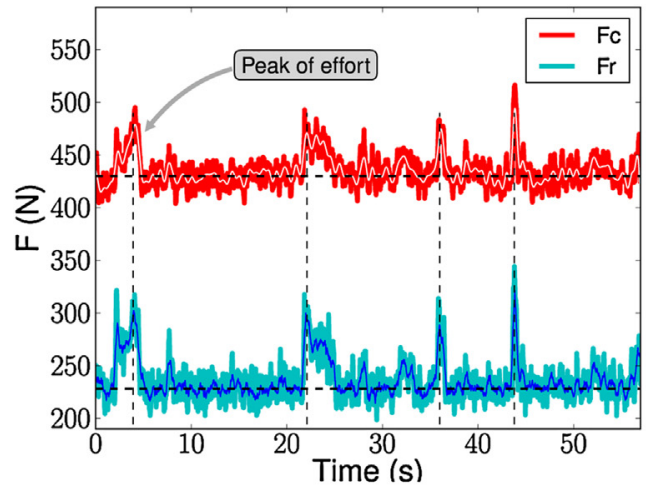

(a)

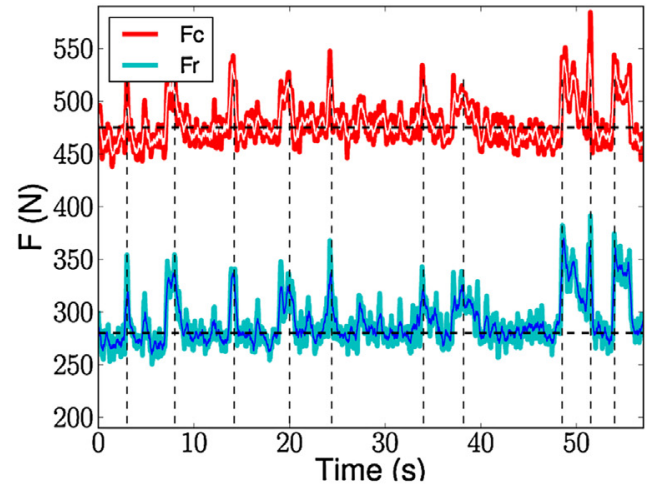

(b)

Fig. 14. Evolution of the cutting and axial forces at 250 bar (a) between 5 min and 6 min, (b) between 9 min and 10 min. 
machining, which results in a catastrophic tool wear. So, even if the two configurations have the same tool life, HP assistance provides better wear control.

Fig. 19(b) shows the evolution of the cutting and the axial forces. For the cutting force, its evolution is the same for both lubrication conditions. The evolution of the axial force seems to follow the evolution of wear. These observations confirm that the axial force of $600 \mathrm{~N}$ is a sign of flank wear of $0.3 \mathrm{~mm}$.

For a tool life of $15 \mathrm{~min}$, the transition from $V_{C}=61 \mathrm{~m} / \mathrm{min}$ (conventional lubrication) to $V_{C}=81 \mathrm{~m} / \mathrm{min}$ (100 bar) signifies an increase in productivity of about $32 \%$. Tool life remains between $9 \mathrm{~min}$ and $15 \mathrm{~min}$ for the cutting speeds of up to $88 \mathrm{~m} / \mathrm{min}$. In this range, Ti17 is not machinable with conventional lubrication.

\section{Conclusion}

This study is focused on the influence of pressure and cutting speed on the effectiveness of the high-pressure water jet assistance. The lubricant pressure has been varied from 50 bar to 250 bar and the cutting speed from $50 \mathrm{~m} / \mathrm{min}$ to $100 \mathrm{~m} / \mathrm{min}$.

The effect of HP assistance is clearly discernible. In fact, experimental tests have shown that tool life can be increased up to 9 times with a pressure of 100 bar. Moreover, beyond a certain cutting speed the material is no longer machinable with conventional lubrication. However, using HP assistance, it is possible to continue machining and even to increase the cutting speed. For the same tool life of $15 \mathrm{~min}$, the cutting speed can be increased by $30 \%$ using HP assistance. The efficiency of water jet assistance decreases with increasing cutting speed.

The influence of wear on the evolution of the cutting forces has been studied. It has been noted that a certain value of the axial force presents a sign of flank wear $(0.3 \mathrm{~mm})$.

It has been remarked that, for pressures beyond 100 bar, scratches on the surface of the workpiece have been noticed. Moreover, welded fragments of chips have been observed on the machined surface, which can be the result of chips recycling phenomenon.

\section{Acknowledgement}

The authors would like to thank the French region "Pays de la loire" for funding the project.

\section{References}

[1] Ayed Y, Germain G, Ammar A, Furet B. Degradation modes and tool wear mechanisms in finish and rough machining of Ti17 titanium alloy under high-pressure water jet assistance. Wear 2013;305(1-2):228-37.
2] Bhatt A, Attia H, Vargas $R$, Thomson V. Wear mechanisms of WC coated and uncoated tools in finish turning of Inconel 718. Tribol Int 2010;43(5-6):1113-21.

[3] Bouchnak TB (Thèse de doctorat) Etude du comportement en sollicitations extrêmes et de l'usinabilitè d'un nouvel alliage de titane aeronautique: le Ti5553. Arts et Métiers Paristech; 2010.

[4] Childs TK, Maekawa TO, Yamane Y. Metal machining theory and applications. Arnold; 2000

[5] da Silva RB, Machado AR, Ezugwu EO, Bonney J, Sales WF. Tool life and wear mechanisms in high speed machining of Ti-6Al-4V alloy with PCD tools under various coolant pressures. J Mater Process Technol 2013;213(8): 1459-64.

[6] Devillez A, Schneider F, Dominiak S, Dudzinski D, Larrouquere D. Cutting forces and wear in dry machining of Inconel 718 with coated carbide tools. Wear 2007;262(7-8):931-42.

[7] Diniz AE, Micaroni R. Influence of the direction and flow rate of the cutting fluid on tool life in turning process of AISI 1045 steel. Int J Mach Tools Manuf 2007;47(2):247-54.

[8] Ezugwu E, Bonney J. Effect of high-pressure coolant supply when machining nickel-base Inconel 718, alloy with coated carbide tools. J Mater Process Technol 2004:1045-50.

[9] Ezugwu E, Silva RD, Bonney J, Machado Ã. Evaluation of the performance of CBN tools when turning Ti-6Al-4V alloy with high pressure coolant supplies. Int J Mach Tools Manuf 2005;45(9):1009-14.

[10] Ezugwu EO, Bonney J, Silva RBD, Cakir O. Surface integrity of finished turned Ti-6Al-4V alloy with PCD tools using conventional and high pressure coolant supplies. Int J Mach Tools Manuf 2007;47(6):884-91.

[11] Hartung P, Kramer B, von Turkovich B. Tool wear in titanium machining. CIRP Ann - Manuf Technol 1982;31(1):75-80.

[12] Kaminski J, Ljungkrona O, Crafoord R, Lagerberg S. Control of chip flow direction in high-pressure water jet-assisted orthogonal tube turning. Proc Inst Mech Eng B: J Eng Manuf 2000;214(7):529-34.

[13] Kramar D, Krajnik P, Kopac J. Capability of high pressure cooling in the turning of surface hardened piston rods. J Mater Process Technol 2010;210(2): 212-8.

[14] Li B. A review of tool wear estimation using theoretical analysis and numerical simulation technologies. Int J Refract Met Hard Mater 2012;35: 143-51.

[15] Machado A, Wallbank J, Pashby I, Ezugwu E. Tool performance and chip control when machining ti6al4v and inconel901 using high pressure coolant supply. Machining Science and Technology 1998:1-12.

[16] Nabhani F. Wear mechanisms of ultra-hard cutting tools materials. Journal of Materials Processing Technology 2001;115(3):402-12.

[17] Nandy A, Gowrishankar M, Paul S. Some studies on high-pressure cooling in turning of Ti-6Al-4V. Int J Mach Tools Manuf 2009;49(2):18298

[18] Teixeira J (Thèse de doctorat) Etude expérimentale et modélisation des évolutions microstructurales au cours des traitements thermiques post forgeage dans l'alliage de titane Ti17. Institut National Polytechnique de Lorraine; 2005.

[19] Venugopal K, Paul S, Chattopadhyay A. Growth of tool wear in turning of Ti-6Al-4V alloy under cryogenic cooling. Wear 2007;262(9-10): 1071-8.

[20] Venugopal K, Paul S, Chattopadhyay A. Tool wear in cryogenic turning of Ti-6Al-4V alloy. Cryogenics 2007;47(1):12-8.

[21] Wanigarathne P, Kardekar A, Dillon O, Poulachon G, Jawahir I. Progressive toolwear in machining with coated grooved tools and its correlation with cutting temperature. Wear 2005;259(7-12):1215-24.

[22] Xue C, Chen W. Adhering layer formation and its effect on the wear of coated carbide tools during turning of a nickel-based alloy. Wear 2011;270(11-12): 895-902. 